\title{
EXPERIMENTAL STUDY OF A CYCLONE SCRUBBER AIR CONDITIONING SYSTEM USING FACTORIAL DESIGN
}

\author{
R. B. Elias, \\ and A. A. B. Pécora \\ Universidade Estadual de Campinas \\ Faculdade de Engenharia Mecânica \\ Cidade Universitária "Zeferino Vaz" \\ Rua Mendeleyev, 200 \\ CEP. 13083-860, Campinas, SP, Brasil \\ rboulos@uol.com.br \\ arai@fem.unicamp.br \\ Received: October 25, 2013 \\ Revised: November 21, 2013 \\ Accepted: December 20, 2013 \\ ABSTRACT

\section{NOMENCLATURE} \\ d diameter of the orifice pressure swirl plate, $\mathrm{mm}$ \\ Es saturation efficiency, dimensionless \\ $\mathrm{L} / \mathrm{G}$ liquid-gas volumetric ratio, $\mathrm{L} / \mathrm{m}^{3}$ \\ $\mathrm{m}_{\mathrm{L}} / \mathrm{m}_{\mathrm{G}}$ water to air mass flow ratio, dimensionless \\ $\mathrm{P}_{\text {atm }} \quad$ atmospheric pressure, $\mathrm{kPa}$ \\ $\mathrm{T}_{\mathrm{db}} \quad$ dry bulb temperature, ${ }^{\circ} \mathrm{C}$ \\ $\mathrm{T}_{\mathrm{wb}} \quad$ wet bulb temperature, ${ }^{\circ} \mathrm{C}$ \\ $\mathrm{x} \quad$ coded independent variable \\ y response variable
}

This work reports the results obtained in the experimental evaluation of an American type cyclone which has been modified and adapted to perform environmental air conditioning by evaporative cooling. Equipment was fitted with nozzles atomizers, which perform the injection of liquid transversely to the gas stream. The tests were carried out following a full factorial design of experiments in order to obtain the influence of the atomizer holes diameter and of the liquid/air flow ratio on the cyclone performance. The diameter of the atomizer insert holes was in the range of 2.8 to $3.6 \mathrm{~mm}$ and the liquid/air flow ratio was from 0.65 to $0.76 \mathrm{~L} / \mathrm{m}^{3}$. The saturation efficiency (Es) of the cyclone was analyzed through the Response Surface Methodology (RSM). Saturation efficiencies between 45.9 and $62.2 \%$ were obtained. The use of statistical techniques allowed the proposition of empirical correlations to predict the behavior of the system regarding the studied operational range. The results show that the cyclone scrubber equipment is a viable alternative to air conditioning for human standards.

Keywords: cyclone scrubber, factorial experimental design, evaporative cooling.

\section{Greek symbols}

$\beta$ regression coefficient

\section{Subscripts \\ i inlet \\ o outlet}

\section{INTRODUCTION}

Indoor air problems are mainly related to inadequate urban planning, design, operation and maintenance of buildings, materials and equipment in buildings, and inappropriate energy saving. Indoor air quality (IAQ) problems affect all types of buildings including homes, schools, offices, health care facilities and other public and commercial buildings (WHO, 1999). Industrial plants, warehouses and laboratories are designed for proper environmental conditions that include temperature, humidity, air motion and air quality in order to provide thermal comfort and high productivity. As a result, air must be conditioned and contaminants must be collected by the air conditioner system to assure the necessary IAQ (ASHRAE, 1999).

Evaporative cooling systems are viable alternatives for air conditioning and they have been used for a long time to provide comfort when outdoor conditions are suitable (Brown, 2000). Also, the equipment is environmentally friendly as electricity usage is just limited to the required water pumping and air circulation. So the use of such equipment can contribute significantly to energy savings. In addition, this kind of climatization process is free from harmful as CFCs or HCFCs.

In the recent past, wet scrubbers have been modified to enhance the efficiency by various techniques (Mohan and Meikap, 2009). Xu et al. (2007) carried out theoretical and experimental investigations to analyze the humidification process in spray tower. Keshavarz et al. (2008) developed an experimental study and simulated the liquid film formation and the influence of nozzles locations on the performance of the spray scrubber in gaseous and particulate scrubbing processes. Bhattacharya et al. (2010) evaluated the thermal performance of a rotating packed bed with a split packing for the evaporative cooling of water. These studies showed that cyclones are used to control the emission of pollutants to the atmosphere. Furthermore, they are widely used for removing particles from fluids because of their simplicity and low costs in terms of construction, operation and energy consumption (Yang and Yoshida, 2004). Cyclone structure and performance were also evaluated by Tan et al. (2009) and Wang et al. (2010). Elsayed and Lacor (2010) used the response surface methodology RSM to 
optimize the cyclone geometrical ratios regarding collection efficiency.

A cyclone scrubber consists of a cyclone and a device to disperse the scrubbing liquid. The cyclone serves as a contact room in which the interaction of dust particles and scrubbing liquid droplets takes place. High separation efficiencies have been possible by using atomizing nozzles in the cyclone to inject liquid water inside the gas stream (Krames and Büttner, 1994). Park and Lee (2009) developed a cyclone scrubber with a rod impact plate and swirl plates to overcame the many drawbacks of conventional cyclones and wet scrubbers.

A numerical modeling of evaporative cooling processes was developed by Kaiser et al. (2005) for cooling towers equipped with pressure nozzle atomizers. Their results showed the importance of the droplet diameter and water/air flow ratio on system efficiency.

The main objective of this work is to present an experimental study of a cyclone scrubber in order to identify the influence of the diameter of the orifice pressure swirl plates (2.8 to $3.6 \mathrm{~mm}$ ) and liquid-gas ratio ( 0.65 to $0.76 \mathrm{~L} / \mathrm{m}^{3}$ ) on saturation efficiency, accordingly to an experiment factorial design.

\section{MATERIALS AND METHODS}

\section{Response Surface Methodology (RSM)}

RSM is a powerful statistical analysis technique which is well suited for modeling complex multivariate processes, in applications where a response is influenced by several variables and the objective is to optimize this response (Montgomery and Runger, 2008). In order to conduct a RSM analysis, one must first to design the experiment; then to identify the experimental parameters to adjust; and finally to define the response parameter to be optimized. Accordingly to Box et al. (1978), once the experiment has been conducted and the recorded data tabulated, the RSM analysis software models the data and attempts to fit a second-order polynomial to data, expressed as:

$$
y=\beta_{0}+\sum_{i=1}^{k} \beta_{i} x_{i}+\sum_{i=1}^{k} \beta_{i i} x_{i}^{2}+\sum_{i} \sum_{j} \beta_{i j} x_{i} x_{j}
$$

where $\beta_{0}, \beta_{\mathrm{i}}, \beta_{\mathrm{ii}}$, and $\beta_{\mathrm{ij}}$ are the regression coefficients for intercept, linear, quadratic and interaction terms, respectively. While $x_{i}$ and $x_{j}$ are the independent variables, that represents studying factors ( $\mathrm{d}$ and $\mathrm{L} / \mathrm{G}$ ), and $\mathrm{y}$ is the response parameter (Es).

\section{Design of Experiment (DOE)}

A second order central composite rotational design was applied to identify the influence of diameter of the orifice pressure swirl plate (d) and liquid-gas ratio (L/G), both in two levels, on saturation efficiency, Es. Table 1 shows the coded levels $(-1$ to +1$)$ and the associated real values adopted for each studied factor.

This design allowed the evaluation of the two main factors ( $\mathrm{d}$ and $\mathrm{L} / \mathrm{G}$ ) and interactions between these factors $(\mathrm{d} x \mathrm{~L} / \mathrm{G})$ besides the calculation of the standard error of the effects and also the magnitude of the Student t-value which are important to explain the data variability.

Table 1. Factors and their design levels for the experiments.

\begin{tabular}{clccc}
\hline \multirow{2}{*}{ Independent Variable } & \multicolumn{3}{c}{ Level } \\
\cline { 2 - 5 } $\mathrm{d}$ & $\begin{array}{l}\text { Diameter of the orifices } \\
\text { pressure swirl plate, } \\
(\mathrm{mm})\end{array}$ & 2.8 & 3.2 & 3.6 \\
$\mathrm{~L} / \mathrm{G}$ & $\begin{array}{l}\text { Liquid-gas ratio, }\left(\mathrm{L} / \mathrm{m}^{3}\right) \\
0\end{array}$ & 0.65 & 0.71 & 0.76 \\
\hline
\end{tabular}

\section{Cyclone Scrubber Configuration and Design}

A schematic diagram of the experimental apparatus is shown in Fig. 1. It has been designed according to the geometric ratios of an American type cyclone (Zajaczkowski, 1971).

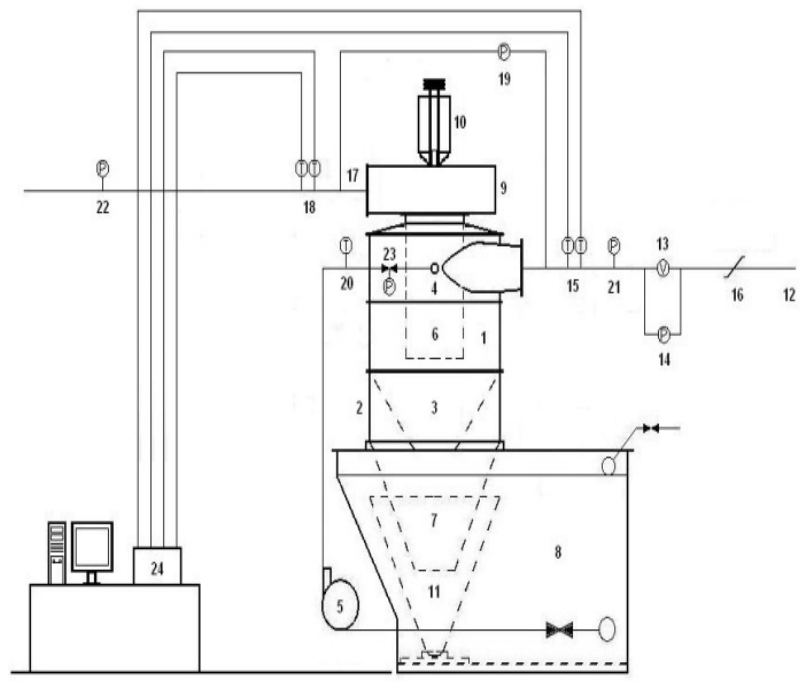

1. Cylindrical body; 2. Adapted Ring (modules); 3. First cone; 4. Spray Nozzles and Bourdon manometers; 5. Electric motor and Pump; 6. Exit duct (cyclone); 7. Second cone; 8. Water box; 9. Exhaustion; 10. Electric motor; 11. Decantation cone; 12. Inlet duct; 13. Orifice plate; 14. Manometer; 15. Wet and dry bulb thermocouples; 16 . Butterfly valve; 17. Exit duct; 18. Wet and dry bulb thermocouples; 19. Manometer; 20. Thermometer; 21. Manometer; 22. Manometer; 23. Bourdon manometer; 24. Digital indicator and computer.

Figure 1. Schematic illustration of the cyclone scrubber.

Unlike the cyclones reported in the literature, the cyclone scrubber showed in Fig. 1 was designed in a modular fashion. The cylindrical body [1] of this cyclone scrubber presents a $0.900 \mathrm{~m}$ diameter. It was made of three ring-shaped modules, each with a height of $0.345 \mathrm{~m}$. The modules are connected to each other by typical flanges, which are sealed using 
rubber gaskets. The lower ring, module [2], is a support for the first [3] and second cones [7]. The first and second modules accommodate nozzles atomizers [4] arranged orthogonally relative to the gas flow. These nozzles are equipped with Bourdon manometers and are connected to the water supply and pressurized by a centrifugal pump [5] drove by a $220 \mathrm{~V}$ and $4.6 \mathrm{~kW}$ motor. The internal gas exit duct [6] is $0.725 \mathrm{~m}$ in height and $0.400 \mathrm{~m}$ in internal diameter. The bottom of the cone is immersed in the water contained in the collecting and purification box [8]. Therefore, the system provides a hydraulic seal that separates the pressurized portion from the other parts under atmospheric pressure. It employs a centrifugal blower [9] drove by a $220 \mathrm{~V}$ and $3.7 \mathrm{~kW}$ electric motor located in the upper portion of the cyclone scrubber, which works under depressurization and provides the suction of gas and dust in order to flow into the equipment.

The cyclone scrubber is assembled above the collection and purification box [8] which presents $1.90 \mathrm{~m}$ length, $0.91 \mathrm{~m}$ wide and $1.05 \mathrm{~m}$ high. Pumping system [5] and feeding nozzles [4] provides the atomizing water through the cylindrical body of the cyclone. After that, the water is conducted to the storage tank, where particle separation occurs by decantation or gravitational forces. In order to accelerate the separation of the pollutants, the storage tank also allows the introduction of flocculants, and thus, purifying the water by chemical means allowing water reuse. The contention box comprises three basic elements. The first is the box that supports the cyclone. The second element is a decantation cone [11] for controlling the water flow rate and collecting the solid particles. A hatch provides access for box cleaning and maintenance. The third element is the discharge valve through which the water/particles are discharged into the sewer when opened. The box capacity is $1.8 \mathrm{~m}^{3}$. A float valve maintains the water level inside the tank. The gas is captured through a 0.22 m diameter circular PVC duct [12] equipped with orifice plate built as ISO-5167 (1989) [13] and a $\mathrm{U}$ manometer to gas flow rate measurement. A butterfly valve [14] at the duct inlet allows the gas flow rate to be controlled. Dry and wet-bulb thermocouples [15] and [18] provide the measurement of inlet and outlet air humidity ratio. The exhaustion duct is rectangular with $0.24 \mathrm{~m}$ wide and $0.325 \mathrm{~m}$ length, meanwhile it changes to a circular duct of $0.310 \mathrm{~m}$ internal diameter at the final portion [17]. Cyclone pressure drop were calculated by a U manometer [19].

Controlled operational parameters were liquid flow (L) and gas flow (G), which define the liquidgas ratio $(\mathrm{L} / \mathrm{G})$. The studied geometric parameter was the diameter of the orifice pressure swirl plate (d). Desired answer (response parameter) was saturation efficiency (Es). Liquid-gas ratio (L/G) was varied by increasing the water flow within the cyclone, while the gas flow was kept constant at $0.552 \mathrm{~m}^{3} / \mathrm{s}$.
The gas humidification was obtained by injected water flow rate in the air flow through one spray nozzle.

Measurements of the cyclone pressure drop and air humidity ratio were made after the steady state was established. Experiments were repeated five times for each operational condition. It was considered that the wet bulb temperature is equal to the adiabatic saturation temperature for all experiments as the operational conditions were controlled in order to make true this assumption.

\section{RESULTS AND DISCUSSION}

Complete experimental data for all the performed tests are presented in Tab. 2. The first column gives the experiment number and the following ones show the measured values as the atmospheric pressure $\left(\mathrm{P}_{\mathrm{atm}}\right)$, inlet and outlet dry bulb temperature $\left(\mathrm{T}_{\mathrm{db}, \mathrm{i}}\right.$ and $\left.\mathrm{T}_{\mathrm{db}, \mathrm{o}}\right)$, inlet and outlet wet bulb temperature $\left(\mathrm{T}_{\mathrm{wb}, \mathrm{i}}\right.$ and $\left.\mathrm{T}_{\mathrm{wb}, \mathrm{o}}\right)$.

Table 2. Measured data.

\begin{tabular}{ccccccc}
\hline \multirow{2}{*}{ Experiment } & & \multicolumn{5}{c}{ Measured values } \\
\cline { 2 - 7 } & & $\begin{array}{c}\mathrm{P}_{\mathrm{atm}} \\
(\mathrm{kPa})\end{array}$ & $\begin{array}{c}\mathrm{T}_{\mathrm{db}, \mathrm{i}} \\
\left({ }^{\circ} \mathrm{C}\right)\end{array}$ & $\begin{array}{c}\mathrm{T}_{\mathrm{wb}, \mathrm{i}} \\
\left({ }^{\circ} \mathrm{C}\right)\end{array}$ & $\begin{array}{c}\mathrm{T}_{\mathrm{db}, \mathrm{o}} \\
\left({ }^{\circ} \mathrm{C}\right)\end{array}$ & $\begin{array}{c}\mathrm{T}_{\mathrm{wb}, \mathrm{o}} \\
\left({ }^{\circ} \mathrm{C}\right)\end{array}$ \\
\hline \multirow{3}{*}{ Factorials } & 01 & 101.0 & 32.2 & 20.2 & 25.4 & 22.4 \\
Tests & 02 & 101.0 & 33.0 & 20.8 & 27.4 & 21.2 \\
& 03 & 102.5 & 36.0 & 21.0 & 28.0 & 22.7 \\
& 04 & 101.0 & 31.9 & 20.5 & 24.8 & 22.2 \\
\hline \multirow{3}{*}{ Axial } & 05 & 101.2 & 35.0 & 21.5 & 27.5 & 23.5 \\
Tests & 06 & 102.5 & 30.0 & 18.0 & 23.5 & 18.5 \\
& 07 & 102.5 & 29.3 & 17.9 & 23.7 & 18.4 \\
& 08 & 102.5 & 30.5 & 18.0 & 23.5 & 19.5 \\
\hline \multirow{2}{*}{ Centrals } & 09 & 102.2 & 35.0 & 20.4 & 27.0 & 21.0 \\
Tests & 10 & 102.5 & 29.0 & 17.5 & 23.0 & 18.0 \\
& 11 & 102.5 & 29.3 & 17.9 & 23.5 & 18.3 \\
& 12 & 102.2 & 36.3 & 19.2 & 26.7 & 19.7 \\
\hline
\end{tabular}

For the performance evaluation system, the efficiency of saturation was calculated by:

$$
E S=\frac{T_{d b, i}-T_{d b, o}}{T_{d b, i}-T_{w b, i}}
$$

Table 3 shows the studied factors and the obtained Es results for all the performed experiments. These data were processed using the software Minitab 14 which allows the analysis of the factors influence and interaction effects on the saturation efficiency. Additional details about analysis of experimental design data are obtained in Neto et al. (2003) and Rodrigues and Iemma (2005). Considering the values obtained during the tests, the maximum experimental uncertainty on Es results was $3.5 \%$. 
Table 3. Factors and responses for the factorial design.

\begin{tabular}{|c|c|c|c|c|c|c|c|}
\hline \multirow{2}{*}{\multicolumn{2}{|c|}{$\begin{array}{c}\text { Experime } \\
\text { nt }\end{array}$}} & \multicolumn{2}{|c|}{$\begin{array}{l}\text { Coded } \\
\text { factors }\end{array}$} & \multicolumn{3}{|c|}{ Real variables } & \multirow{2}{*}{$\begin{array}{c}\text { Response } \\
\text { Es } \\
(\%)\end{array}$} \\
\hline & & d & $\mathrm{L} / \mathrm{G}$ & $\begin{array}{c}\mathrm{d} \\
(\mathrm{mm})\end{array}$ & $\begin{array}{c}\mathrm{L} / \mathrm{G} \\
\left(\mathrm{L} / \mathrm{m}^{3}\right)\end{array}$ & $\begin{array}{c}\mathrm{m}_{\mathrm{L}} / \mathrm{m}_{\mathrm{G}} \\
(-)\end{array}$ & \\
\hline \multirow{4}{*}{ 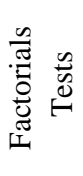 } & 01 & -1 & -1 & 2.8 & 0.65 & 0.59 & 56.6 \\
\hline & 02 & 1 & -1 & 3.6 & 0.65 & 0.59 & 45.9 \\
\hline & 03 & -1 & 1 & 2.8 & 0.76 & 0.68 & 53.3 \\
\hline & 04 & 1 & 1 & 3.6 & 0.76 & 0.68 & 62.2 \\
\hline \multirow{4}{*}{ 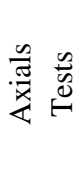 } & 05 & -1 & 0 & 2.8 & 0.71 & 0.64 & 55.6 \\
\hline & 06 & 1 & 0 & 3.6 & 0.71 & 0.62 & 54.2 \\
\hline & 07 & 0 & -1 & 3.2 & 0.65 & 0.56 & 49.1 \\
\hline & 08 & 0 & 1 & 3.2 & 0.76 & 0.67 & 56.0 \\
\hline \multirow{5}{*}{ 苞量 } & 09 & 0 & 0 & 3.2 & 0.71 & 0.63 & 54.8 \\
\hline & 10 & 0 & 0 & 3.2 & 0.71 & 0.62 & 52.2 \\
\hline & 11 & 0 & 0 & 3.2 & 0.71 & 0.62 & 50.9 \\
\hline & 12 & 0 & 0 & 3.2 & 0.71 & 0.63 & 56.1 \\
\hline & 13 & 0 & 0 & 3.2 & 0.71 & 0.63 & 54.8 \\
\hline
\end{tabular}

\section{Analysis of the Saturation Efficiency}

Saturation efficiency was analyzed through the Response Surface Methodology (RSM). The analysis and the construction of the regression model for Es were performed using the significant terms of the calculated P-values and the Pareto diagram of the effects, which shows the magnitude of the parameter t-Student (t) at 95\% confidence level (or 5\% significance level). Linear terms are associated to the letter $(\mathrm{L})$ and the quadratic terms to the letter $(\mathrm{Q})$.

The Pareto diagram (Fig. 2) shows the statistical significance of the effects in a descending order of importance. The statistical significance of the variables is evaluated by observing whether the horizontal bars representing the factors interactions, are beyond the vertical reference line on the level of significance of the P-value (indicated by a dashed line in Fig. 2).

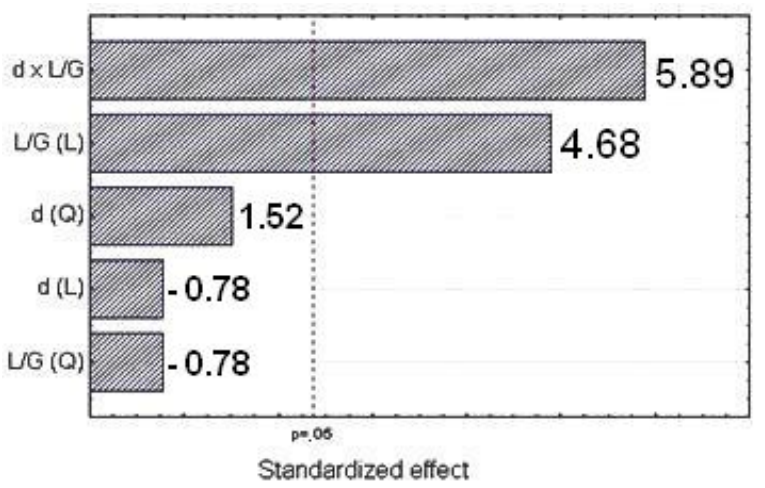

Figure 2. Pareto Chart for Saturation Efficiency (Es).

Figure 2 shows that the interaction term [d x L/G] and the linear term of L/G ratio [L/G (L)] have significant impact on increasing Es.
According to Rodrigues and Iemma (2005), the interaction factor provides a measure of dependency between the factors under study. Regarding the range of the present experimental conditions, the saturation efficiency was not affected by the diameter of the orifice of the pressure swirl plate, i.e. [d (Q)], [d (L)], or by the quadratic term of the $\mathrm{L} / \mathrm{G}$ ratio $[\mathrm{L} / \mathrm{G}(\mathrm{Q})]$.

The analysis of variance for Es showed a standard error of the effects equal to $82.48 \%$ which indicate that a model could be obtained from acceptable data variability.

The descriptive statistics led to the construction of surface and contour plots which are presented in Fig. 3. The effect of the independent variables on the dependent ones are visualized in the surface response of the quadratic polynomial model generated.

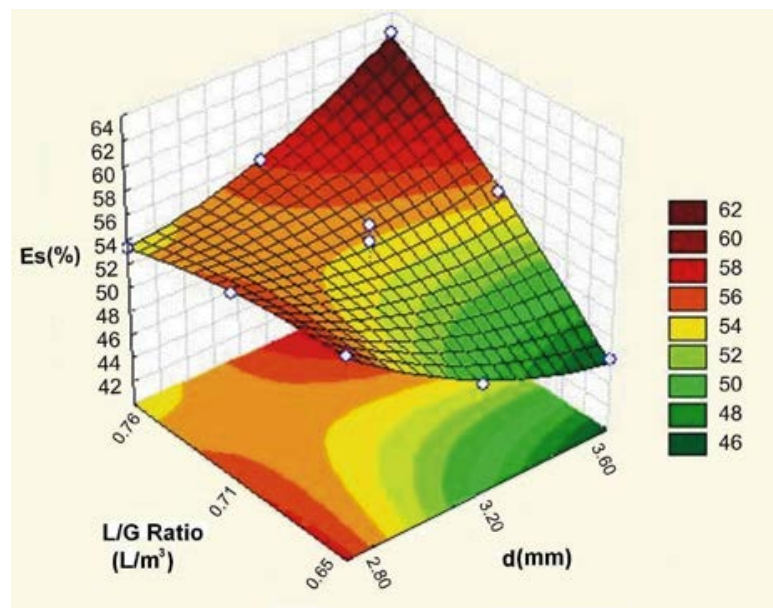

Figure 3. Surface plot for saturation efficiency (Es).

The maximum efficiency is approximately $62.2 \%$, which was obtained for the $3.6 \mathrm{~mm}$ hole diameter nozzle and $\mathrm{L} / \mathrm{G}$ of $0.76 \mathrm{~L} / \mathrm{m}^{3}$.

The fitted polynomial model for $E s$ is represented by:

$$
\begin{aligned}
& \text { Es }=515.94-157.82 d-651.03(L / G) \\
& +222.25 d(L / G)
\end{aligned}
$$

Equation (3) was provided by regression analysis from the real values of the factors $d$ and $L / G$.

\section{Comparison with Literature Data}

Values of saturation efficiency ranging between $45.9 \%$ and $62.2 \%$ were obtained in the present research. These values were compared with those reported by Kaiser et al. (2005) who found results between $44.3 \%$ and $48.1 \%$ for a HVAC system with spray directly into a environment at $35.0^{\circ} \mathrm{C}$ dry bulb temperature and $25.6^{\circ} \mathrm{C}$ wet bulb temperature.

In the present study, the water to air mass flow ratio $\left(\mathrm{m}_{\mathrm{L}} / \mathrm{m}_{\mathrm{G}}\right)$ ranged from 0.56 to 0.68 (Tab. 3), while for Kaiser et al. (2005) it varied between 0.54 and 1.57. Results show that the saturation efficiencies 
obtained in the present work were higher than those obtained by Kaiser et al. (2005) with the additional advantage of using smaller water and mass flow ratios as shown in Fig. 4.

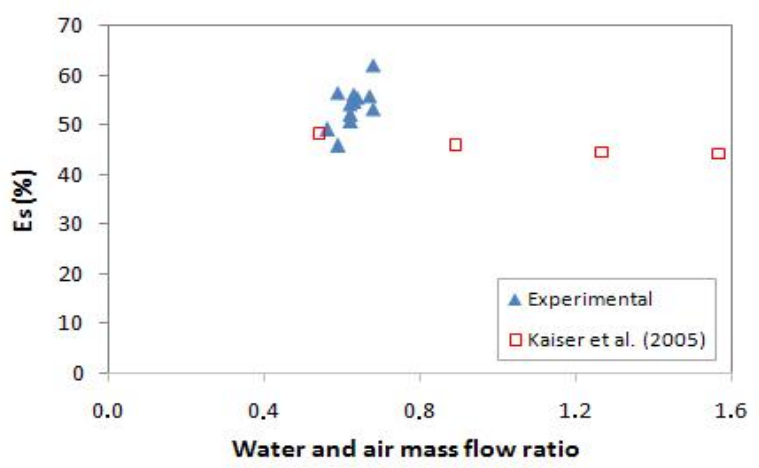

Figure 4. Efficiency of saturation in function of water and air mass flow ratio.

\section{CONCLUSIONS}

RSM investigation has been used to understand the effect of the pressure swirl plate orifice diameter (d) and liquid-gas ratio (L/G) on the saturation efficiency (Es) of an American type cyclone scrubber.

Interaction term between $\mathrm{d}$ and $\mathrm{L} / \mathrm{G}$ ratio as the linear term of $\mathrm{L} / \mathrm{G}$ ratio had a significant impact on Es. The results also allowed obtaining an empirical model represented by Eq. (3) to predict the saturation efficiency in the studied range.

The interaction between the diameter of the holes of the pressure swirl plate and L/G ratio shows that these factors influence each other, which is a relevant result to the equipment design.

\section{REFERENCES}

ASHRAE, 1999, Ashrae Applications Handbook, American Society of Heating, Refrigerating and Air-Conditioning Inc. Atlanta.

Bhattacharya, S., Mondal, A., Bhowal, A., and Datta, S., 2010, Evaporative Cooling of Water in a Rotating Packed Bed (Split Packing), Industrial \& Engineering Chemistry Research, Vol. 49, No. 2, pp. 847-851.

Box, G. P., Hunter, W. G., and Hunter, J. S., 1978, Statistics for Experimenters, New York, Wiley.

Brown, W. K., 2000, Operation and Maintenance ff Evaporative Coolers, Ashrae Journal, Vol. 7, pp. 37-32.

Elsayed, K., and Lacor, C., 2010, Optimization of the Cyclone Separator Geometry for Minimum Pressure Drop using Mathematical Models and CFD Simulations, Chemical Engineering Science, Vol. 65, pp. 6048-6058.

ISO-5167, 1989, Measurement of Fluid Flow by means of Orifice Plates, Nozzles and Venturi Tubes
Inserted in Circular Cross-section Conduits Running Full, International Organization for Standardization.

Kaiser, A. S., Lucas, M., Viedma, A., and Zamora, B., 2005, Numerical Model of Evaporative Cooling Processes in a New Type of Cooling Tower, International Journal of Heat and Mass Transfer, Vol. 48, pp. 986-999.

Keshavarz, P., Bozorgi, Y., Fathikalajahi, J., and Taheri, M., 2008, Prediction of the Spray Scrubbers Performance in the Gaseous and Particulate Scrubbing Processes, Chemical Engineering Journal, Vol. 140, pp. 22-31.

Krames, J., and Büttner, H., 1994, The Cyclone Scrubber - A High Efficiency Wet Separator, Chem. Eng. Technol., Vol. 17, pp. 73-80.

Mohan, B. R., and Meikap, B. C., 2009, Performance Characteristics of the Particulate Removal in a Novel Spray-Cum-Bubble Column Scrubber, Chemical Engineering Research and Design, Vol. 87, pp. 109-118.

Montgomery, D. C., and Runger, G. C., 2008, Estatística Aplicada e Probabilidade para Engenheiros ( $2^{a} E d$.), Rio de Janeiro, RJ, Brasil, LTC. (in Portuguese)

Neto, B. D., Scarmino I. S., and Bruns, R. E., 2003, Como Fazer Experimentos: Pesquisa $e$ Desenvolvimento na Ciência e na Indústria ( ${ }^{a}$ Ed.), Campinas, SP, Brasil, Editora da Unicamp. (in Portuguese)

Park, S.-H., and Lee, B.-K., 2009, Development and Aplication of a Novel Swirl Cyclone Scrubber (2) Theoretical, Journal off Hardadous Materials, Vol. 164, pp. 315-321.

Rodrigues, M. I., and Iemma, A. F., 2005, Planejamento de Experimentos e Otimização de Processos ( $1^{a}$ Ed.), Campinas, SP, Brasil, Ed. Casa do Pão. (in Portuguese)

Tan, Z., Zhang, H., Abedi, J., Yu, Z., and Martinuzzi, R., 2009, Development of a New HighEfficiency Simple Structure Cyclone, The Canadian Journal of Chemical Engineering, Vol. 87, pp. 343349.

Wang, W., Zhang, P., Wang, L., Chen, G., Li, J., and Li, X., 2010, Structure and Performance of the Circumfluent Cyclone, Powder Technology, Vol. 200, pp. 158-163.

WHO, 1999, Strategic Approaches to Indoor Air Policy-Making, Copenhagen, Denmark.

Xu, Z., Xiao, Y., and Wang, Y., 2007, Experimental and Theoretical Studies on Air Humidification by a Water Spray at Elevated Pressure, Applied Thermal Engineering, Vol. 27, pp. 2549-2558.

Yang, K.-S., and Yoshida, H., 2004, Effect of Mist Injection Position on Particle Separation Performance of Cyclone Scrubber, Separation and Purification Technology, Vol. 37, pp. 221-230.

Zajaczkowski, J., 1971, Odpylanie W Przemysle, Warszawa, Arkady. 